\title{
The oxidation behaviour of mixed tungsten silicon sputtered coatings
}

\author{
C. Louro*, A. Cavaleiro

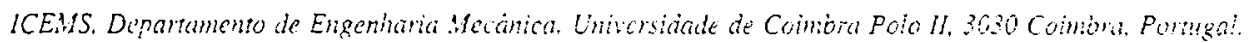

\begin{abstract}
W-Si-N coatings were deposited by sputeting and their chemical composition. structure. thermal and oxidation beiaviour were characterised. Si-containing fiims are essentially amorphous. $W_{3,} S_{i} ;$ fim crystallises at $750^{\circ} \mathrm{C}$ as $\alpha-W$ and $W_{5}$ Sis phases whereas no significan: structura! iransformations were observed for $\mathrm{W}_{24} \mathrm{Si}_{2}, \mathrm{~N}_{5}$ flim up to $1000^{\circ} \mathrm{C}$. In both cases elemental difusion (Si and $\mathrm{N}$ ) for the suostrate was detected after thermal annealing. These coatings present much betier oxidation resistance than $W$ and $W$. Coatings. T 1999 Elsevier Science S.A. Ail rights reserved.
\end{abstract}

Keywords: Oxidation resistance: Silicides: W-S;-Niñms: Tungsten silicide: Spuitering

\section{Introduction}

Owing to the excelient mechanical properties of bulk tungsten compounds, extensive research work has been carried out in the last decade to deposit VV-based materials under the form of thin coatings, particular'y by PVD techniques.

In previous research work [1], we demonstrated that $W$ and $W-N$ coatings suffer extensive oxidation degradation for temperatures higher than $700^{\circ} \mathrm{C}$. Moreover, it was possible to conciude that the addition of $\mathrm{Ti}$ or $\mathrm{Ni}$ to $\mathrm{W}-\mathrm{N}$ coatings could increase their oxidation resistance, for the same degree of degradation. at iemperatures some tens of ${ }^{\circ} \mathrm{C}$ higher.

The addition of silicon has a beneficial role on the oxidation behaviour of materials. For example. Hirvonen et ai. [2] demonstrated that amorphous Mo-Si coatings deposited by sputtering resist up to $1000^{\circ} \mathrm{C}$ in oxidant environments. However, this resistance was oniy observed for the ñlms containing nitrogen.

Thus the objective of this research work was;

- to deposit W-based coatings by sputtering with and without Si and $\mathrm{N}$.

- to characterise the coatings concerning their structure. chemical composition and therma! behaviour.

- to evaluate and to try to understand the role of Si and $\mathrm{N}$ on the oxidation resistance of the films.

* Corresponding althor.

\section{Experimental details}

\subsection{Deposition technique}

The films were denosited by DC reactive magnerron sputtering with a specific target power density of $10 \mathrm{~W} / \mathrm{cm}^{2}$ anc a negative substrate bias of $70 \mathrm{~V}$. The target is pure $W$ $(150 \times 150 \mathrm{~mm})$; for the deposition of $\mathrm{W}-\mathrm{Si}$ films round pieces of pure silicon 11 min thick $)$ were glued on the target. When the reaciive mocie was used the $N$-Ar partial pressure ratio was $2 / 1$ and $1 / 1$ for $W-N$ and $W-S i-N$ films. respecively, for a totai deposition pressure of 0.3 Pa. The substrates of stee! (318 - AISI) were polished on both faces with diamond paste cown to a particle size of $1 \mu \mathrm{m}$. Before deposition. the sputering chamber was evacuated by a turbomolecular pump down to a final pressure of $10^{-4} \mathrm{~Pa}$. The substrate surfaces were then ion cleaned by an ion gun.

\subsection{Characterisation techmiques}

Thermogravimetric tests were camied out on a Polymer Science thermobalance of high resoiution $(0.1 \mu g)$. Oxidation temperatures ranged from $600-1000^{\circ} \mathrm{C}$. The samples were heated up to the oxidation temperature at a fixed heating rate of $30^{\circ} \mathrm{C} \mathrm{min}{ }^{-1}$. A constant isothermal time of 30 $\min$ was used. Industria: air of $99.995 \%$ purity was used as oxidant gas.

The structure of the films was anaiysed by $X$-ray diffraction (XRD) using a Siemens diffractometer with $\mathrm{C}_{\mathrm{n}}-\mathrm{K}_{n}$ radiation. This equipment was provided with a fumace allowing the samples to be heated up to $1200^{\circ} \mathrm{C}$. Thermal aanealing of the films was carried out in a vacturis with 

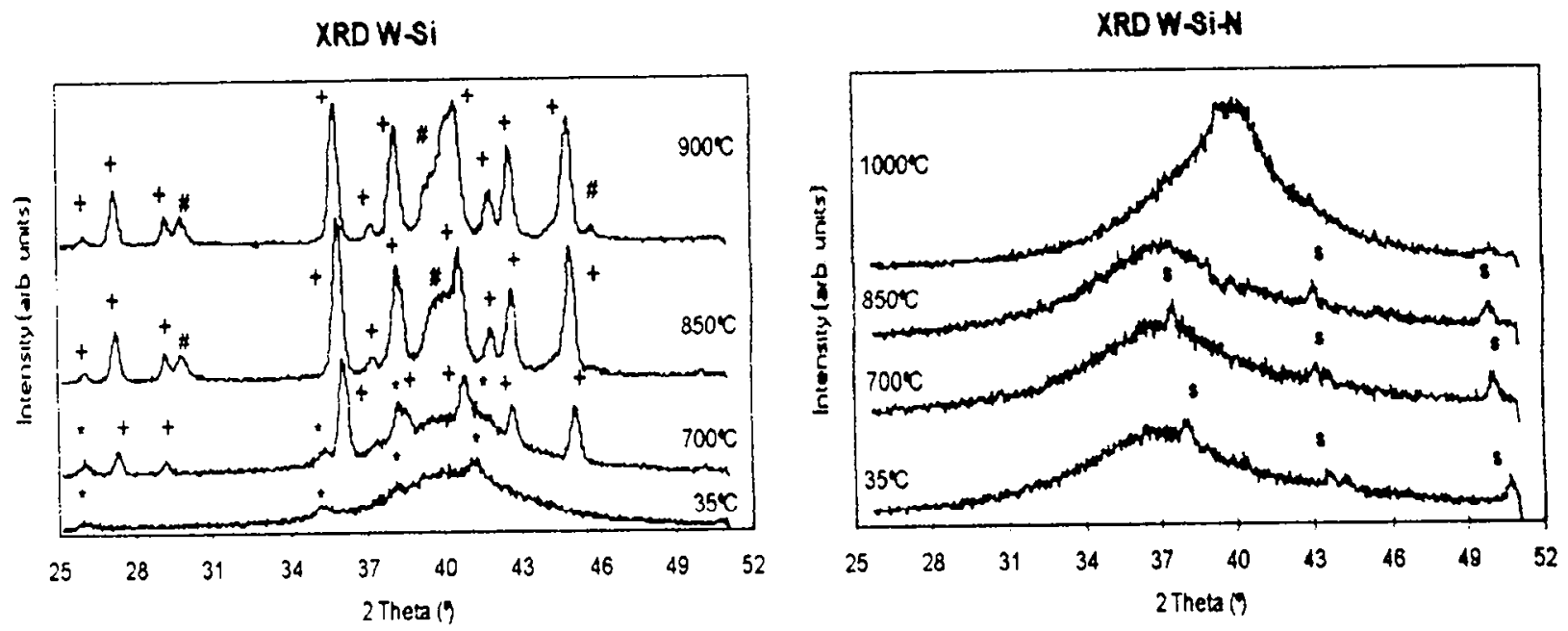

Fig. 1. In situ XRD diffractograms of W-Si and W-Si-N sputtered films taken at increasing annealing temperatures (only the diffractugram's greatest characteristics are shown). s. substrate: ${ }^{*}$. WSi, hexagonal;,$- W_{j} \mathrm{Si}_{j} ; \#, \mathrm{WSi}_{2}$ tetragonal.
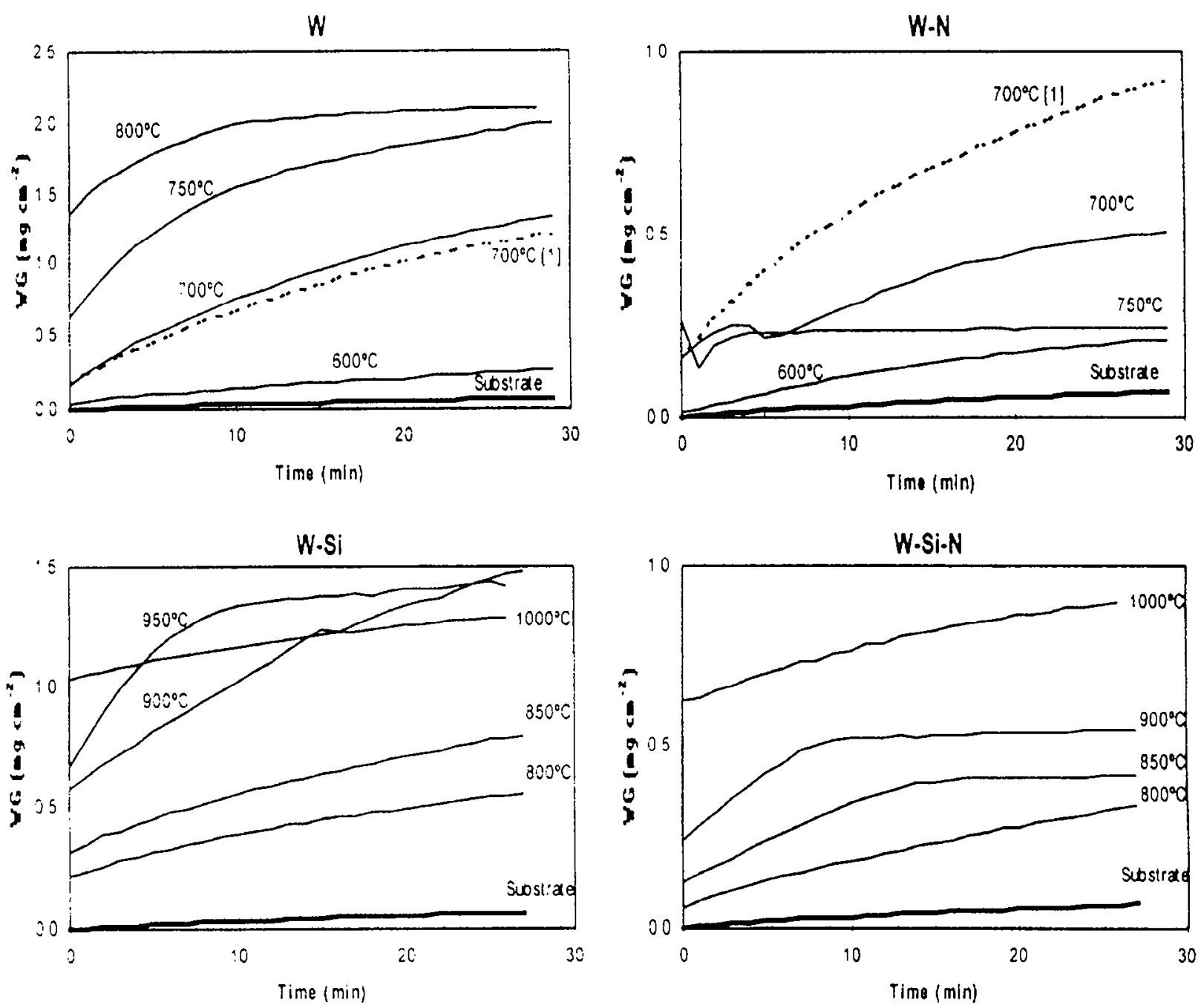

Fig. 2. Isothermal oxidation curves of $W, W-N . W-S i$ and $W-S i-N$ tilms. The curve for the substrate oxidised at $1000^{\circ} \mathrm{C}$, as well as the curves for $W$ and $W-N$ films oxidised at $700^{\circ} \mathrm{C}$ and characterised in previous work [1], is also shown. 
XRDW

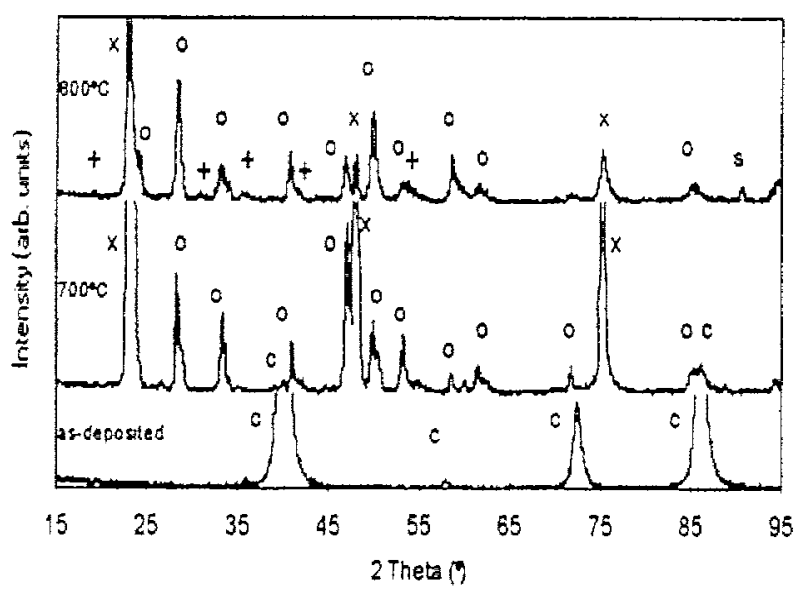

XRDWSi

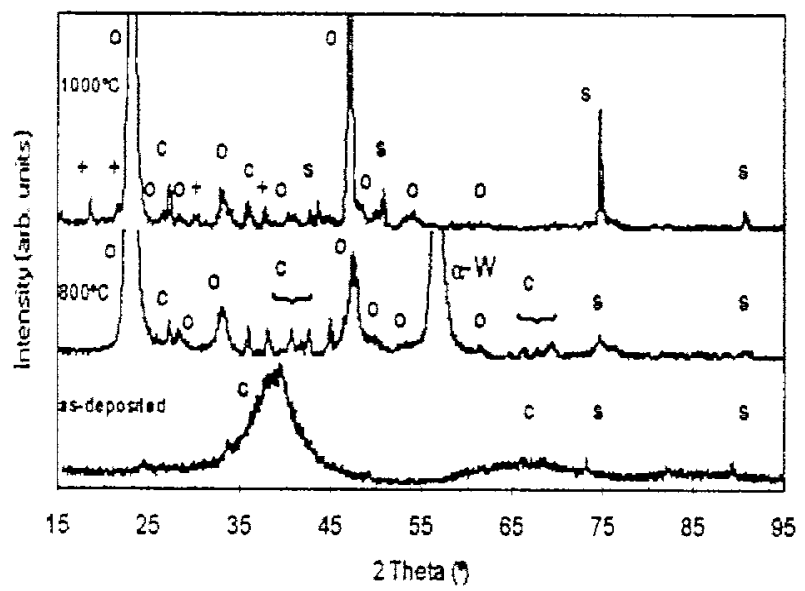

XRDWN

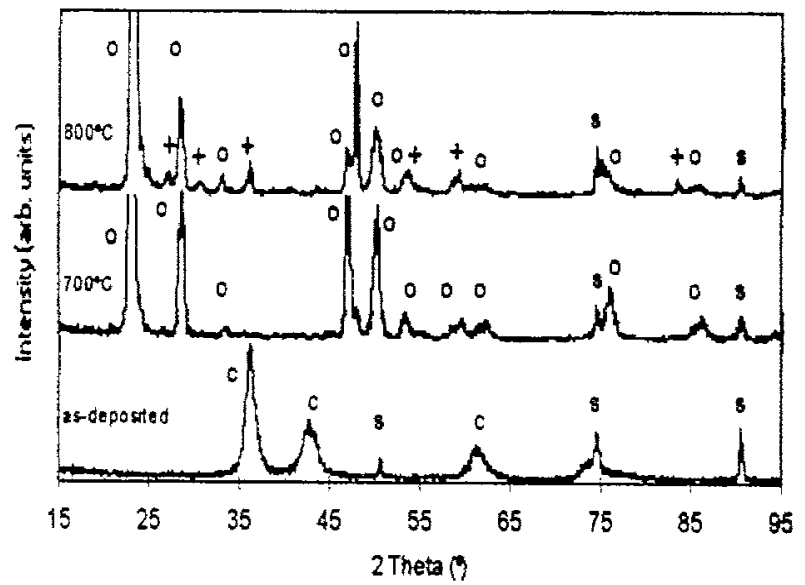

XRD WSINN

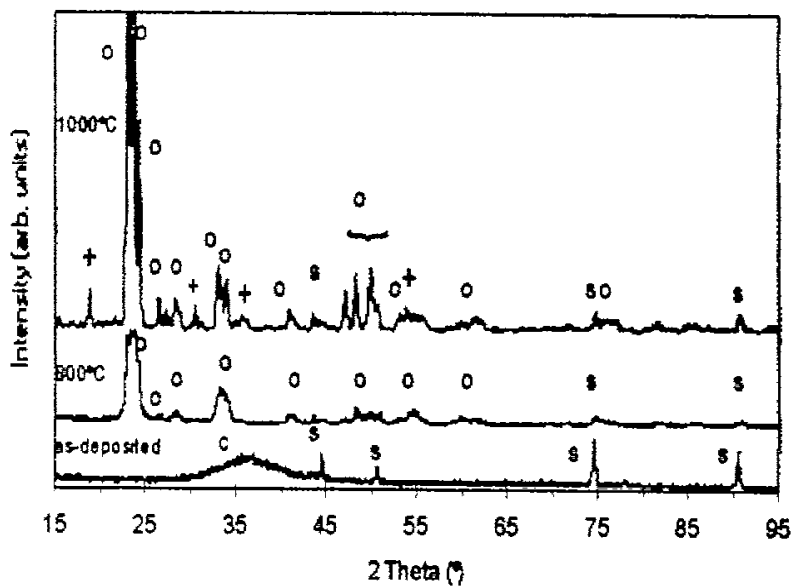

Fig. 3. Structural evolution of W (a), W-N (b), W-Si (c) and W-Si-N (d), with oxidation temperature; $o, \mathrm{WO}_{3} ; x$, WO $;+$, FeWO $\mathrm{O}_{4} ; c$, coating; $s$, substrate.

increasing temperatures up to $1000^{\circ} \mathrm{C}$ under a continuous flow of a gas mixture of $\mathrm{Ar}+\mathrm{H}_{2}$. X-ray diffractograms were taken at steps of $100^{\circ} \mathrm{C}$ in the range $\left[T_{\text {an b }}-600^{\circ} \mathrm{C}\right]$, $50^{\circ} \mathrm{C}$ in the range $\left[600-900^{\circ} \mathrm{C}\right]$ and $25^{\circ} \mathrm{C}$ in the range $\left[900-1000^{\circ} \mathrm{C}\right]$.

A Cameca SX-50 electron probe microanalysis (EPMA) apparatus was used to determine the chemical composition of the coatings.

The cross-section of the films, its surface topology and morphological details were examined in a Jeol T330 scanning electron microscope (SEM). This apparatus was connected to an energy-dispersive X-ray detector (EDXS) (Tracor Instruments).

\section{Results and discussion}

\subsection{As-deposited coatings}

The chemical composition of the films was determined by
EPMA as $\mathrm{W}, \mathrm{W}_{45} \mathrm{~N}_{55}, \mathrm{~W}_{69} \mathrm{Si}_{31}$ and $\mathrm{W}_{24} \mathrm{Si}_{2 \mathrm{i}} \mathrm{N}_{55}$. Concerning the $\mathrm{Si}$ content, as was observed for other $\mathrm{W}-\mathrm{N}$ films, the presence of $\mathrm{N}$ makes the resputtering of the silicon during the deposition more difficult owing to the ion bombardment induced by the substrate bias. Consequently, a lower W/Si deposition rate is obtained for $\mathrm{W}-\mathrm{Si}-\mathrm{N}$ in comparison to W-Si films.

In agreement with the chemical composition, the films without $\mathrm{Si}$ present the b.c.c. $\alpha-\mathrm{W}$ phase and the nitride phase, $W_{2} N$, for the films without and with nitrogen, respectively. However, in this last case, the nitride indexed does not correspond to the nitrogen content in the film, indicating that some free nitrogen should be present in excess in the nitride lattice.

Both films containing Si have mainly amorphous structures. However, in the film without $\mathrm{N}$ it is possible to observe signs of hexagonal $\mathrm{WSi}_{2}$ superimposed on the broad amorphous diffraction peak. If the amorphism of the films should be expected taking into account literature results and the Si content of the films [3-5], the hexagonal 

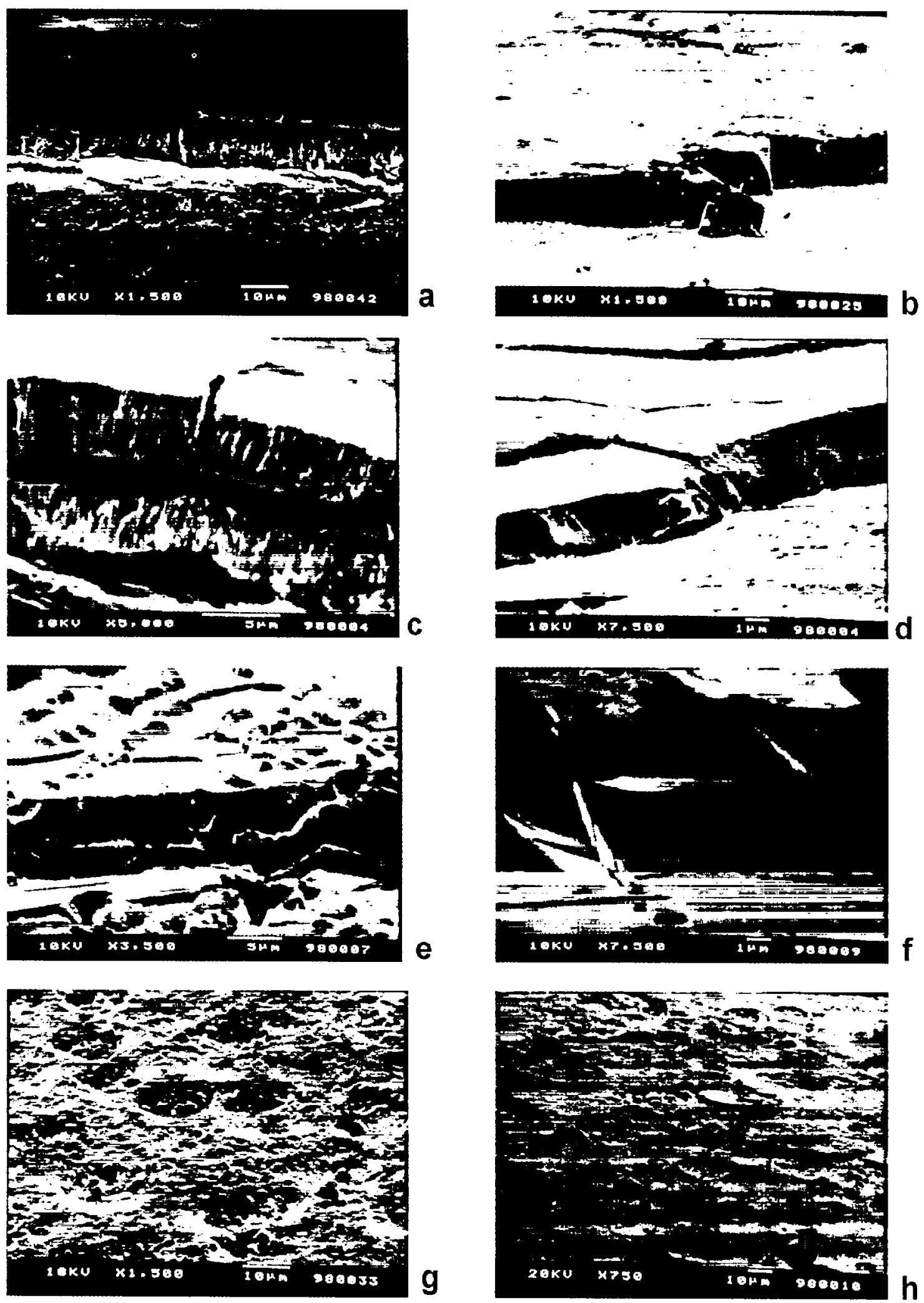

Fig. 4. SEM micrographs of the cross-section or surface morphologies of the oxide layers of: (a) W hilms oxidised at $750^{\circ} \mathrm{C}$ for $30 \mathrm{~min}$, (b) $\mathrm{W}^{\prime}-\mathrm{Si}$ film oxidised at $950^{\circ} \mathrm{C}$ for $30 \mathrm{~min}$. (c) as-deposited $W$, (d) as-deposited W-N. (e) as-deposited W-Si. (f) as-deposited W-Si-N. (g) W-N nilm oxidised at $700^{\circ} \mathrm{C}$ for 30 min (h) $\mathrm{W}-\mathrm{Si}-\mathrm{N}$ film oxidised at $900^{\circ} \mathrm{C}$ for $30 \mathrm{~min}$. 
$\mathrm{WSi}_{2}$ was not found, to our knowledge, in the literature. Moreover, this phase, although with the highest Si content of the W-Si phases, was detected in the film with a higher $\mathrm{W} / \mathrm{Si}$ ratio, not being indexed for $\mathrm{W}-\mathrm{Si}-\mathrm{N}$ flim. However, it is referred to in the literature $[5,6]$ that the structure of W-Si materials depends on the processing conditions, it being possible to obtain $\mathrm{WSi}_{2}$ in materials with low $\mathrm{Si}$ content [6].

In order to interpret the results of the oxidation at high temperatures it was necessary to study the thermal evolution of these amorphous films. Fig. 1 shows X-ray diffractograms for increasing annealing temperatures. In the case of $\mathrm{W}-\mathrm{Si}$ film, crystallisation begins at $700^{\circ} \mathrm{C}$ with the formation of $\mathrm{W}_{5} \mathrm{Si}_{3}$ and $\alpha-\mathrm{W}$ phases. This result is very close to that of Reid et al. [4] for similar chemical compositions. At $850^{\circ} \mathrm{C}$, the transformation of pre-existing hexagonal into tetragonal $\mathrm{WSi}_{2}$ was observed. This temperature is much higher than that of $600^{\circ} \mathrm{C}$ indicated in the work of LeGoues et al. [7], probably owing to their much higher silicon content $(\mathrm{W} / \mathrm{Si}=0.5)$.

The W-Si-N film does not suffer appreciable changes with increasing annealing temperatures up to $1000^{\circ} \mathrm{C}$. The structure remains amorphous and only some changes in the position and form of the amorphous peak are observed. Up to $900^{\circ} \mathrm{C}$ there are small shifts in the peak position for low diffraction angles (due to the temperature increase), but for higher temperatures, there are important shifts in the inverse sense. Moreover, the peak narrows, probably indicating the beginning of crystallisation. Hirvonen et al. [2] found similar behaviour for $\mathrm{Mo}-\mathrm{Si}-\mathrm{N}$ films suggesting that these changes should be related to the relaxation and densification of the structure. They aiso detected a loss of nitrogen in the film towards the substrate. Our measurements by EPMA on the films after thermal annealing showed a $25 \%$ decrease of the initial $\mathrm{N}$ content and an increase in the W/Si value from 1.1 to 1.3 , indicating that Si diffuses into the substrate. It should be remarked that this loss of $\mathrm{Si}$ was also observed for W-Si films; a W/Si value of 2.5 was found instead of the original 2.2 .

\subsection{Oxidation behaviour}

Fig. 2 presents the isothermal mass change data for $\mathrm{W}-$ $\mathrm{Si}-\mathrm{N}$ coated samples. In all the cases, the uncoated substrate behaviour for $1000^{\circ} \mathrm{C}$ is also shown. XRD diffractograms obtained from the oxidised films are presented in Fig. 3 for the different oxidation temperatures. Some important remarks can be made after a careful analysis of these figures:

- The oxidation resistance of the coatings containing $\mathrm{Si}$ is much higher than for $\mathrm{W}$ and $\mathrm{W}-\mathrm{N}$ films, although no significant differences could be observed in the type of oxides detected by XRD. However, it should be pointed out that during the oxidation of silicides the protective scale is $\mathrm{SiO}_{2}$ and this phase exists in the amorphous state for temperatures lower than $1000^{\circ} \mathrm{C}$ [8]. Thus, it is probable that if a layer of $\mathrm{SiO}_{2}$ exists it may not be detected by XRD. Another possible explanation is related to the density of the oxide layer. The oxide layers of the films containing Si are much more compact than those of the $W$ and $W-N$ films, as can be observed in Fig. $4 a, b$.

- This compact morphology should not be related to the asdeposited cross-section morphologies. In fact, excepting single $W$ that presents a type 1 morphology following Thornton's classification, all the coatings, including W$\mathrm{N}$, are very dense (Fig. $4 \mathrm{c}-\mathrm{f}$ ).

- As would be expected, the oxidation behaviour of $W$ is very similar to that obtained in previous work [1], whereas for $\mathrm{W}-\mathrm{N}$ some changes can be observed, probably due to its higher $\mathrm{N}$ content. In this case, there is a severe cracking of the oxide layers during the test, particularly for temperatures higher than $700^{\circ} \mathrm{C}$, leading to the fall off of some oxide particles from the sample holder and the sudden weight losses in the oxidation curves (Fig. 2). This is clearly shown in the picture presented in Fig. $4 \mathrm{~g}$. The $\mathrm{N}$ liberation during oxidation, in association to residual stresses in the as-deposited and oxide layers, promote oxide cracking. For higher temperatures, similar cracking is also observed for the W-Si-N films (Fig. 4h).

- For the highest oxidation temperatures the coatings with Si do not show the same total oxidation weight gains in spite of having the same as-deposited thickness. Moreover, the final stage of oxidation is not coincident with the substrate oxidation. This behaviour should be related to the inter-diffusion of elements ( $\mathrm{Si}, \mathrm{Fe}$ and $\mathrm{N}$ ) between the film and the substrate. In consequence, when the oxidation reaches the substrate, this does not have the original composition, and, consequently, its oxidation behaviour should be different.

- The presence of crystallised phases in the W-Si film oxidation at $850^{\circ} \mathrm{C}$ should be noted, in agreement with the thermal annealing results presented above.

\section{Conclusions}

The introduction of $\mathrm{Si}$ in $\mathrm{W}-\mathrm{N}$ sputtered films leads to amorphous structures.

- $\mathrm{W}_{24} \mathrm{Si}_{21} \mathrm{~N}_{55}$ films keeps an amorphous structure up to $1000^{\circ} \mathrm{C}$ whereas $W_{6 y} \mathrm{Si}_{21}$ crystallises at $750^{\circ} \mathrm{C}$ as $\alpha-W$ and $\mathrm{W}_{5} \mathrm{Si}_{3}$.

- Si-containing films have better oxidation resistance than $\mathrm{W}$ and $\mathrm{W}-\mathrm{N}$ coatings which is promising for applications where the service temperature is higher than $800^{\circ} \mathrm{C}$.

\section{References}

11] C. Louro, A. Cavaleiro, J. Electrochem. Soc. 144 (1997) 259.

[2] J.P. Hirvonen, I. Suni, H. Kattelus, Surf. Coat. Technol. 74 (1995) 981.

[3] A.G. Lahay, C.S. Wu, J. Vac. Sci, Technol. B 6 (1988) 1765. 
[+] J.S. Reid. E. Kolawa. R.P. Ruiz. M.A. Nicolet, Thin Solid Films 236 $11993) 319$.

[5] M.L. Ger. R.B. Broun. J. Mater. Res. 10 (1995) 1710

[6] S. Gede Vanishvili. Z.A. Munir. J. Mater. Res. 10 (1995) 2642.
[7] F.K. LeGoues, F.M. d'Heurle, R. Joshi, I. Suni, Mater. Res. So. Symp. Proc. S+ (1986) 51.

[8] D. Bertziss. R.R. Cerchiara. E.A. Gulbransen. F.S. Pettit. G.H. Meier. Mater. Sci. Eng. A 155 (1992) 165. 